\title{
Improving energy performance of a Cement Manufacturing factory by using Waste Heat Recovery Systems, Estimated vs. Actual achievements
}

\author{
Mircea Scripcariu ${ }^{1}$, Cristian Gheorghiu ${ }^{2}$, Miruna Gheorghiu ${ }^{3}$ and Alexandra Gabriela \\ Dobrica $^{4 *}$ \\ ${ }^{1}$ University Politehnica of Bucharest, Energy Production and Use Department, 313 Splaiul \\ Independentei, Bucharest, Romania \\ ${ }^{2}$ University Politehnica of Bucharest, Energy Production and Use Department, 313 Splaiul \\ Independentei, Bucharest, Romania \\ ${ }^{3}$ ELSACO ESCO L.L.C.,500 Mihai Bravu, Bucharest, Romania \\ ${ }^{4}$ University Politehnica of Bucharest, Energy Production and Use Department, 313 Splaiul \\ Independentei, Bucharest, Romania
}

\begin{abstract}
Waste Heat Recovery (WHR) Systems are spreading more and more in cement factories and are essential in achieving the energy performance required by the European Directives, legislation, and standards. Using WHR Systems may assure an important percentage of the energy required by the manufacturing process, with no additional fuel and no additional greenhouse gas emissions. Using the waste heat as a power generation source, increases the energy efficiency of the process and decreases the thermal energy losses. As long as the kiln is functional, so is the WHR powerplant, generating the energy in an efficient manufacturing process with low operational costs and increased reliability. This paper aims at evaluating the actual technic and economic performance of a WHR System compared to the estimated performance determined in the feasibility study which was done prior to the investment in order to prove the viability of the technology in the cement manufacturing industrial sector. The paper proves that the WHR proved to be financially inefficient if the feasibility study input data was considered and correlated with the actual technical performance but lead to extremely attractive financial indicators when considering actual, updated capital expenditures and operational expenditures and technical performance.
\end{abstract}

\section{Introduction}

Currently there are numerous technical solutions available for a cement factory which can reduce the carbon footprint and improve the energy performance of the process. Using the best available technology may increase the energy performance of the process but, a high amount of energy is still demanded by the process. In 2020, the largest cement 'Corresponding author: alexandra.dobrica3@gmail.com 
manufacturer worldwide reported a total energy consumption of 528 million of GJ. Fig. 1 shows the amount of thermal energy and electricity demand [1]. The purpose of the Organic Rankine Cycle System is to reduce the costs of energy extracted from the national electric power grid by having a reliable power source on-site. The first 1.5 MW ORC system was installed in Lengfurt in 1999 [2]. Since then, the technology had been used in many cement factories from 49 countries having 402 plants operating in 2021.

The cement manufacturers focused their attention on ORC technology because it has proven its energy performance and it has reduced the high amount of greenhouse gas emissions generated by this industry.
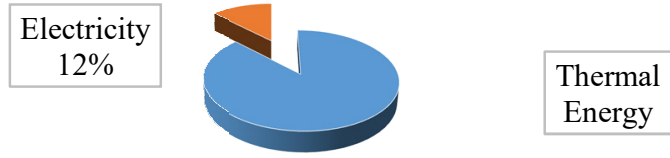

Fig. 1. Thermal energy and electricity use reported by the biggest cement manufacturer.

The cement industry has a significant environmental footprint due to the high amount of thermal energy required by the process, mainly coming from the burning of traditional fuels. In the last 25 years, the $\mathrm{CO}_{2}$ emissions produced by the cement industry increased drastically, from $27 \mathrm{Gt}$ in 2006 to $32 \mathrm{Gt}$ in 2020 . Without a sustainable strategy to reduce the greenhouse gas emissions, the quantity of $\mathrm{CO}_{2}$ could achieve over $36 \mathrm{Gt}$ after 2022, as shown in the Figure 2 [3]. 50\% of $\mathrm{CO}_{2}$ emissions are produced during the calcination process, in which the limestone is transformed into lime as an outcome of a chemical reaction [3]. About $40 \%$ of the total quantity of $\mathrm{CO}_{2}$ are produced as a result of the burning processes required to achieve the $1,450{ }^{\circ} \mathrm{C}$ temperature of clinkerization. The rest of $10 \%$ of the greenhouse gas emissions are the result of electricity needed to run the plant [3]. To reach the target proposed by the Green Deal, a carbon neutral Europe by 2050 and reduce the $\mathrm{CO}_{2}$ emissions in the cement sector with $30 \%$ by 2030 , the industry has the opportunity to invest in kiln upgrades and waste heat recovery using ORC systems [4].

Fig. 2. Total energy related to $\mathrm{CO}_{2}$ emissions with and without a sustainable recovery, 2005-2023 [3].

\section{From Waste Heat to Power}

In 2011, the first ORC system in Romania was operational. The system was installed on a $4,300 \mathrm{t}$ /day rotary kiln. The ORC system has an installed power of $4.1 \mathrm{MW}$. In the first phase of the project, many key factors were taken into account, such as: temperatures from the process, waste heat energy potential, the working fluid, time allocated for the kiln inspection etc. [6]. Temperature is a high importance factor for the system because it has an influence on the power plant design, materials, heat exchangers for the system [7], and on 
the energy potential of the waste heat source. The main advantage of the system is its capacity to operate at relatively low temperatures of steam in comparison with the conventional steam cycle. The temperature at the preheater outlet is $360{ }^{\circ} \mathrm{C}$, while at the clinker cooler the temperature is lower, the average temperature is around $250{ }^{\circ} \mathrm{C}$, as shown in Figure 3.

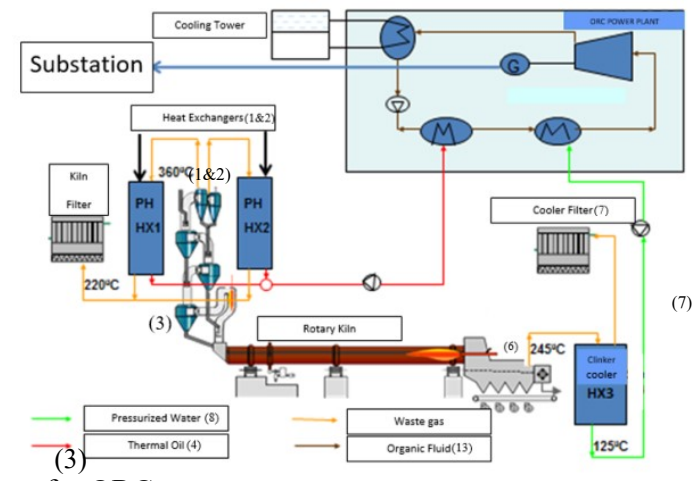

Fig. 3. Waste Heat Sources for ORC system

(6)

The thermodynamic circuit is described in Figure 4. The preheater boilers ( 1 and 2$)$ of the ORC system are extracting the ${ }^{(8)}$ waste gas after the superior stage cyclones (3), returning it before the fans after the gas has transferred the heat to the heat to the thermal oil (4) used as working fluid, while the clinker cooler boiler (5) is installed between clinker cooler (6) and the filter (7). The heat from the main heat exchanger from the kiln is extracted with two horizontal cross flow boilers (1 and 2), using thermal oil as heat transfer fluid and one vertical gas flow boiler with dust settling chamber, using pressurized water as heat transfer fluid (8). By using pressurized water, the boiler's "capacity" decreased with $20 \%$. This combined solution of having thermal oil in the preheater boilers and hot pressurized water in the clinker cooler boiler as working fluids is a new technical solution for the ORC systems in the cement industry [7]. The ORC unit uses the working fluids to pre-heat and vaporize the organic working fluid in the evaporator. The organic fluid vapor powers the turbine (9), which is directly coupled to the electric generator (10), generating electricity. The exhaust vapor flows through the regenerator (11) where it preheats the organic liquid (12). The vapor is then condensed in the condenser (13) which has a water-cooling system (14). In the last transformation of the organic cycle, the organic fluid is pumped in the regenerator (15) and then to the evaporator (16).

During the estimation phase of the ORC project, some assumptions were made in order to investigate the performance of the system. To estimate the available heat for the plant, a production rate of $3,800 \mathrm{t} /$ day and an average heat consumption during normal operation of $3,396 \mathrm{MJ} / \mathrm{t}_{\text {clinker }}$. Because the power output of the ORC system depends on the preheater exit temperature, a couple of upgrades had to be implemented to the rotary kiln: Chlorine bypass and solid recovered fuel feeding to the calciner. The initial results, along with the implemented upgrades, had shown a waste gas flow of $1.6 \mathrm{Nm}^{3} / \mathrm{kg}_{\text {clinker }}$ at the preheater, representing a waste heat source for the future ORC system. The maximum thermal energy output at the preheater was estimated at $36.5 \mathrm{MW}$, this output is obtained in ideal conditions during one year operation time at a $20{ }^{\circ} \mathrm{C}$ outside temperature as reference, an average temperature $366{ }^{\circ} \mathrm{C}$ at the preheater outlet and a gas flow of $253,328 \mathrm{Nm}^{3} / \mathrm{h}$ at the preheater. 


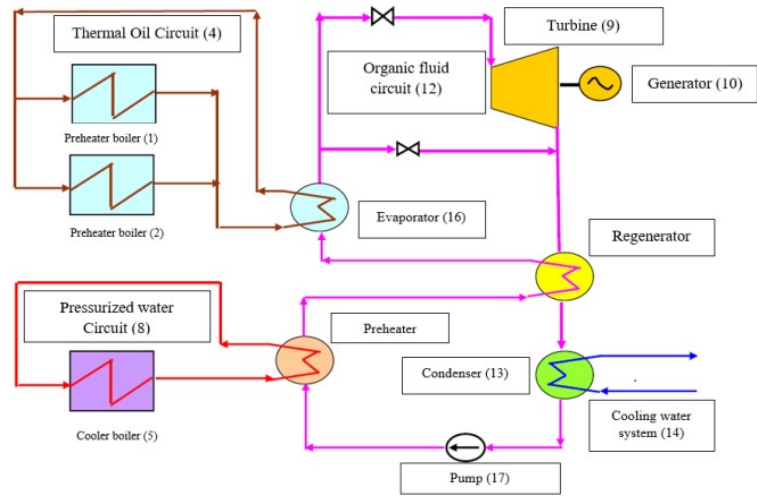

Fig. 4. ORC thermodynamic circuit

In the non-ideal case, during operation, the monthly thermal energy output it is expected not to exceed more than 21.6 MW because of the seasonal changes of the outside temperature. The same assumptions were made to calculate the maximum thermal energy output from the clinker cooler, resulting a cooler waste gas of $0.8 \mathrm{Nm}^{3} / \mathrm{kg}_{\text {clinker }}$ at an average air temperature of $250{ }^{\circ} \mathrm{C}$ inside the cooler. The results had shown that waste air flow is $126,666 \mathrm{Nm}^{3} / \mathrm{h}$ generating a peak power of $10.7 \mathrm{MW}$. As in the preheater case, the waste thermal energy output in non-ideal conditions at the clinker cooler will not exceed 4.1 MW. The initial costs of the project were estimated in the feasibility study, the results are shown in the table 2. The operational costs and the maintenance ones were estimated at 100 $\mathrm{kEUR} / \mathrm{yr}$. In the financial evaluation of the project, the expected lifetime was considered 20 years and the availability of the plant at $97 \%$, resulting the financial indicators from table 3 .

Table 1. Natural Gas and Electricity consumption for each Brick Factory

\begin{tabular}{|c|c|c|}
\hline Technical Characteristic & Measuring Unit & Value \\
\hline Available thermal energy & MW & 21.3 \\
\hline Gross electricity production & MW & 3.8 \\
\hline Net electricity production & MW & 3.5 \\
\hline Gross efficiency & $\%$ & $18[8]$ \\
\hline Net electricity production at 95\% availability of the plant & GWh/year & 27.0 \\
\hline
\end{tabular}

Table 2. Initial cost of the ORC system

\begin{tabular}{|r|l|c|r|r|}
\hline \multicolumn{4}{|c|}{ Initial costs for the power plant } \\
\hline \multicolumn{2}{|c|}{ Project stage } & Currency & Amount & Percent \\
\hline 1 & Land preparation and infrastructure & kEUR & 100 & $1 \%$ \\
\hline 2 & Engineering, supervision, commissioning & kEUR & 500 & $4 \%$ \\
\hline 3 & Equipment & kEUR & 11,500 & $82 \%$ \\
\hline 4 & Civil part & kEUR & 600 & $4 \%$ \\
\hline 5 & Contingencies & kEUR & 1,300 & $9 \%$ \\
\hline $\mathbf{6}$ & Total Project Investment Cost & kEUR & $\mathbf{1 4 , 0 0 0}$ & $\mathbf{1 0 0 \%}$ \\
\hline
\end{tabular}

Table 3. Estimated financial indicators.

\begin{tabular}{|c|c|}
\hline Indicator & Value \\
\hline NPV & 4.7 million EUR \\
\hline IRR & $16.2 \%$ \\
\hline Dynamic Payback & 12.5 years \\
\hline
\end{tabular}




\section{Actual performance of the ORC system}

After six years in operation, the Organic Rankine Cycle system has achieved its expected performance. The plant is still operational, covering 15\% [9] of the electrical energy demanded by the cement factory. Because the system is designed to operate at low temperatures, the ORC is a much more suitable solution for cement industry in comparison with the conventional steam cycle [10]. After years of monitoring the main parameters of the plant, discrepancies were observed in comparison with the performances described in the initial study. In the estimations phase of the project, the availability of the plant was considered $95 \%$, meaning 7,500 $\mathrm{h} / \mathrm{yr}$. The actual availability time of the plant had an average value of 7,200 h/yr, with $300 \mathrm{~h} / \mathrm{yr}$ less than the expected time. It is very important to specify that the lower availability time is the came as a consequence of the direct interdependence between the ORC plant and the rotary kiln operation, and it should not be considered as a break-down time due to ORC system malfunction. Having an overview on the actual energy performance of the plant, the following were observed:

- The specific waste air flow from the clinker cooler has the actual measured value of $0.942 \mathrm{Nm}^{3} / \mathrm{kg}_{\text {clinker }}$ at a temperature of $240{ }^{\circ} \mathrm{C}$, representing an increased flow and a decreased temperature in comparison with the one given in the estimation phase.

- The specific waste gas flow from the preheater has a measured value of 1.090 $\mathrm{Nm}^{3} / \mathrm{kg}_{\text {clinker }}$, less than the $1.8 \mathrm{Nm}^{3} / \mathrm{kg}_{\text {clinker }}$ expected in the estimation phase. The outlet temperature of the preheater is $397{ }^{\circ} \mathrm{C}$ instead of $360{ }^{\circ} \mathrm{C}$ which represents the calculated temperature of the waste gas coming from the preheater.

- The amount of thermal energy which can be recovered from the process is approximatively $18.5 \mathrm{MW}$, representing half of the thermal energy calculated in the ideal conditions of operation.

- The gross electrical power output has the actual value of $3.1 \mathrm{MW}$, resulting a a gross efficiency of $17 \%$, representing a close performance in comparison with the estimated value of $18 \%$.

Table 4. Actual energy performances of the ORC plant

\begin{tabular}{|c|c|c|}
\hline Technical Characteristic & Measuring Unit & Value \\
\hline Available thermal energy & MW & 18.5 \\
\hline Gross electricity production & MW & 3.1 \\
\hline Net electricity production & MW & 2.9 \\
\hline Gross efficiency & $\%$ & 17 \\
\hline Net electricity energy production at 95\% availability of the plant & GWh/year & 24.7 \\
\hline
\end{tabular}

Considering the lower energy performance compared to those estimated in the feasibility study, the actual production of the power was lower than the electricity production forecast calculated in the feasibility study. The comparison between the actual production and the forecast is presented in figure 5. Regarding the economic aspects, the real maintenance cost did not exceed the estimated cost of $100 \mathrm{kEUR} / \mathrm{yr}$, even though many revisions and inspections were done using external resources which were more expensive than expected in the estimation phase. The annually maintenance using internal and external resources cost are presented in table 5. In order to compare the forecasted financial viability of the project with the actual financial viability, an Actual Scenario analysis was done. The main criterions used in the technic and economic analysis were the Net Present Value - NPV (1), the Internal Rate of Return - IRR (2), the Simple Payback Period - SPP (3), determined by considering a variable annual net income and the Benefit - Cost Analysis - BCA (4). 


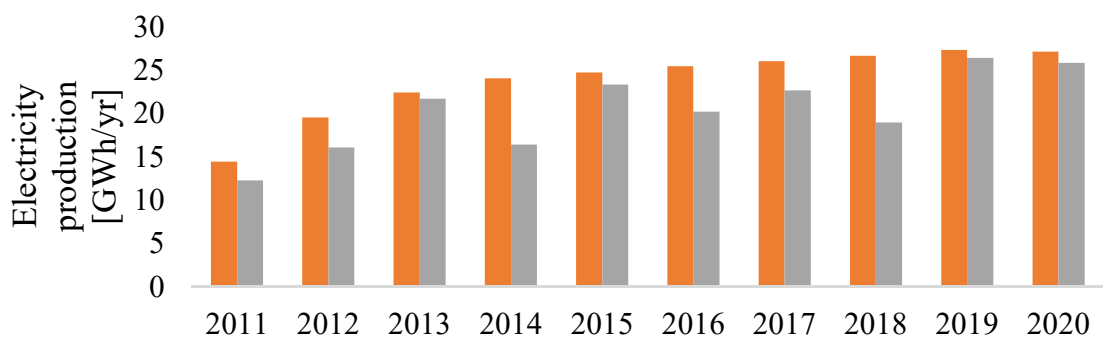

Fig. 5. Estimated (orange) vs. Actual (gray) production of the ORC

Table 5. Actual maintenance cost of the ORC plant

\begin{tabular}{|c|c|l|l|l|l|l|l|}
\hline Year & Cost & $\begin{array}{l}\text { I. } \\
\text { Maintenance } \\
\text { activities with } \\
\text { own } \\
\text { resources: }\end{array}$ & $\begin{array}{l}\text { II. } \\
\begin{array}{l}\text { Maintenance } \\
\text { activities } \\
\text { using external } \\
\text { resources: }\end{array}\end{array}$ & $\begin{array}{l}\text { Inspections } \\
\text { and } \\
\text { revisions }\end{array}$ & $\begin{array}{l}\text { Pump } \\
\text { fixing }\end{array}$ & $\begin{array}{l}\text { Other } \\
\text { repairing } \\
\text { activities }\end{array}$ & $\begin{array}{l}\text { TOTAL } \\
\text { (I+II): }\end{array}$ \\
\hline 2013 & {$[\mathrm{kEUR}]$} & 8.88 & 7.55 & 2.79 & 3.26 & 1.50 & 16.43 \\
\hline 2014 & {$[\mathrm{kEUR}]$} & 8.51 & 6.06 & 1.58 & - & 4.48 & 14.57 \\
\hline 2015 & {$[\mathrm{kEUR}]$} & 9.37 & 51.35 & 50.73 & - & 0.62 & 60.73 \\
\hline
\end{tabular}

$$
N P V=\sum_{t=1}^{t s t} \frac{I_{t}-C_{t}}{(1+a)^{t}}-I C[E U R]
$$

where $t_{\text {tst }}$ is the analysis time-frame, in years, $I_{t}$ is the yearly income in the $t^{\text {th }}$ year, in EUR/year, $\mathrm{C}_{\mathrm{t}}$ are the yearly expenditures in the $\mathrm{t}^{\text {th }}$ year, in EUR/year, $\mathrm{a}$ is the discount rate $-11.38 \% /$ year for this end-user and IC is the investment cost, in EUR.

$$
N P V=\sum_{t=1}^{t s t} \frac{I_{t}-C_{t}}{(1+I R R)^{t}}=0[E U R]
$$

where the CAPEX can be included in the yearly expenditures as a depreciation cost.

$$
\begin{gathered}
S P P=\frac{I C}{\frac{\sum_{i=1}^{t} I_{i}-C_{i}}{t}}[\text { years }] \\
B C A=\frac{I C}{N P V}[-]
\end{gathered}
$$

An average escalation rate for electricity prices of 5\%/year was also considered, as determined in [11]. The technic economic analysis results will be presented in Table 6.

Because, as it can be observed in Table 6, the financial indicators of the project in the Actual Scenario turns out to be unfeasible for the company, a Present Day Scenario was also analyzed in order to quantify the differences generated by the maturity of the ORC technology. Because the project was implemented in 2011 (only 21 years after the first ORC was deployed in the cement industry sector), the technology was still new, and the benefit / cost forecast stage of the feasibility study was not accurate. The CAPEX of the 
project was also considerably higher than it would be today (an average specific cost decrease of 914.63 EUR/kW from 3,414 EUR/kW in 2011 to 2,500 EUR/kW in 2021).

Table 6. Comparative Financial Analysis

\begin{tabular}{|c|c|c|c|}
\hline Financial Indicator & Feasibility Study & "Actual" scenario & "Present day" scenario \\
\hline CAPEX [EUR] & $14,000.000 .00$ & $14,000.000 .00$ & $10,500.000 .00$ \\
\hline OPEX [EUR/year] & $120,000.00$ & $60,730.00$ & $60,730.00$ \\
\hline $\begin{array}{c}\text { Average Annual Benefits } \\
\text { [EUR/year] }\end{array}$ & N/A & $1,817.969 .89$ & $3,304.934 .66$ \\
\hline NPV [EUR] & $4,700.000 .00$ & $-2,884.775 .69$ & $9,984.237 .28$ \\
\hline IRR [\%] & 16.90 & 8.65 & 21.55 \\
\hline SPP [years] & N/A & 12.02 & 6.31 \\
\hline BCA [-] & N/A & 0.79 & 1.95 \\
\hline
\end{tabular}

As it can be observed, the scenario in which the project was developed and deployed in 2021 would lead to more attractive financial indicators, even when properly quantifying the OPEX and the average annual benefits. This is mainly due to the maturity of the ORC technology and to the almost linear increase of the electricity price both in the $2011-2021$ period and in the $2021-2040$ forecast. In the feasibility study, the project may seem more attractive because the initial scenario is also quantifying the annual benefits of using the ORC system as a combined heat and power plant. The generated heat would have been used for administrative buildings and preparation of hot water. In other industries, the thermal energy produced by an ORC system is already valorized, improving the financial performance of the projects [12]. Even if the ORC system appears to be not feasible in the "actual" scenario, its contributions to reducing the annual $\mathrm{CO} 2$ emissions cannot be ignored. So far, the annually $\mathrm{CO}_{2}$ reduction was approximatively $15,400 \mathrm{tCO}_{2} / \mathrm{yr}$, economy which came as a result of the electricity generated without additional fuel. Regarding the differences in the OPEX between the feasibility study forecast and the actual registered costs, it was observed that the turbine of the power plant was the most reliable part of the system but, the most failures came from the generator break-down and leaks of the organic fluid, which is a high toxicity organic compound. The failure time has a strong impact on the power plant electricity production because of fewer running hours - some failures needed up to one week to be solved. Beside those unexpected events, another discrepancy between the availability time of $95 \%$ in the initial study and the actual operation of the plant is represented by the longer time needed for the rotary kiln inspection. Some inspections exceeded 2.5 months until completion, so the kiln was not functional during those months, making the ORC plant unavailable. The electricity production of the ORC system was also smaller in the "Actual" scenario compared to the forecast of the feasibility study. The main reason is that the plant is situated in the moderate-continental climate, the outside temperature during the cold season drops below $0^{\circ} \mathrm{C}$ (significantly lower than the average $20^{\circ} \mathrm{C}$ ISO reference temperature used for estimation). This, in turn, leads to a decrease in the waste heat extracted from the kiln, thus to a decrease of available thermal energy. Currently there are projects meant to increase the ORC capacity in the next few years. The cement manufacturer aims to increase the waste heat available for the plant with more upgrades on the rotary kiln. A higher daily production rate will produce more heat which can be recovered from de plant. An increased capacity will assure a high amount of electricity with no additional fuel and no greenhouse gas emissions which is a main issue nowadays. 


\section{Conclusions}

In this paper, the energy performance of a 4.1 MW ORC plant was emphasized. The project meant to increase the energy efficiency was a success, despite the discrepancies between the initial estimation and the actual achievements. The system has proven its reliability, being a fully automated system with few break-down times during operation. Because of the similarities with the conventional steam cycle, there were no new additional knowledge requirements needed in order to assure the plant operation. Based on the lessons learned, $t$ can be concluded that in order to make ORC technology more attractive and increase its penetration rate both in the cement industry and in other buildings materials industries, a number of adjustments have to be done in the feasibility stage:

1. The kiln (heat source) capacity must be better estimated - both in terms of operability and in terms of evolution over time,

2. The electricity production forecast must be done by considering the seasonal variation of various external factors, such as the outdoor temperature, as it strongly influences the efficiency of the system,

3. The operational costs of the system have to more accurately evaluated - both in terms of various parts and subsystem feasibility and in terms of actual costs for maintenance, capital works etc.,

4. The management of the company (both the Top Management and the Factory Management) have to get more involved in the feasibility study stage in order to properly evaluate various hypothesis made by the consultancy team and to mitigate the eventual misassumptions.

\section{References}

1. LafargeHolcim, Integrated Sustainability Report, (2020).

2. H. Legmann, "Recovery of Industrial Heat in the Cement Industry by Means of the ORC Process," $44^{\text {th }}$ IEEE-IAS/PCS Cement Industry Technical Conference,5-9 May, pp 29-35, Florida, ISBN 0-7803-7254-9, (2002).

3. International Energy Agency, "Total energy related $\mathrm{CO} 2$ emissions with and without a sustainable recovery, 2005-2023," (2020).

4. European Commission, "Cement, waste and carbon markets. Problems related to waste incineration in cement kilns under the EU-ETS," (2020).

5. Cembureau - The European Cement Association, „Cementing the European Green Deal", (2020).

6. Institute for Industrial Productivity, "Waste Heat Recovery for the Cement Sector: Market and Supplier analysis Waste Heat Recovery for the Cement Sector", (2014).

7. M. Poerner and A. Rimpel, "Waste heat recovery," in "Fundamentals and Applications of Supercritical Carbon Dioxide (SCO2) Based Power Cycles", Woodhead Publishing, pp. 255-267, DOI: 10.1016/B978-0- 08-100804-1.00010, (2017).

8. S. Quoiilin, M. V. D. Broek, S. Declaye, P. Dewallef and V. Lemort, "Technoeconomic survey of Organic Rankine Cycle (ORC) systems," "Renewable and Sustainable Energy Reviews", vol. IV, no. 22, pp. 168-186, (2012).

9. R. Menz, "From Waste Heat To Power," International Cement Review, no. 10, pp. 5962, (2012).

10. S. Karellas, "Energetic and exergetic analysis of waste heat recovery systems in the cement industry," Energy, no. 58, pp. 147-156, (2013). 
11. Ioan-Sevastian Bitir-Istrate, Cristian Gheorghiu and Miruna Gheorghiu, "The Cost of Indecision in Energy Efficiency. A Cost of Opportunity Analysis for an Industrial Consumer," 55th International Scientific Conference on Information, Communication and Energy Systems and Technologies (ICEST), DOI: 10.1109/ICEST49890.2020.9232894, (2020)

12. M. Scripcariu, I. Bitir-Istrate, M. Butu, R. Porumb, A. Pavel, M. Patrascan, "Heat recovery in metallurgy. Technical and economical aspects of using ORC installations in Romania," 6th International Conference on Thermal Equipment, Renewable Energy and Rural Development, June 8-10, Romania, ISSN 2359-7941, pp.: 149-154, (2017). 